\title{
REAVI
}

Universidade do Estado de Santa Catarina

Centro de Educação Superior do Alto Vale do Itajaí

\section{ESTUDO E PROPOSTA DE ICONOGRAFIA ADEQUADA PARA USO EM APLICAÇÕES MULTIMODAIS INCLUSIVAS DE CONCESSIONÁRIAS DE ENERGIA ELÉTRICA}

\author{
Tiago Cinto ${ }^{1}$, Ismael Ávila ${ }^{1}$, Fabiani de Souza ${ }^{1}$, Elaine Hayashi ${ }^{1}$ \\ ${ }^{1}$ Fundação Centro de Pesquisa e Desenvolvimento em Telecomunicações - CPqD \\ tiagoci@cpqd.com.br, avilan_an@cpqd.com.br, fabiani@cpqd.com.br, elaineh@cpqd.com.br
}

\begin{abstract}
Resumo
Atualmente estima-se que $15 \%$ da população mundial tenham algum tipo de deficiência física ou sensorial e que mais de $20 \%$ tenham baixos níveis de letramento, inclusive digital. Numa época marcada pela informatização dos serviços, por novos aplicativos e dispositivos computacionais cada vez mais rápidos, a inclusão desse público em ambientes digitais ainda enfrenta muitas barreiras, e grande desse público ainda se encontra fora da sociedade informacional. Muitas iniciativas vêm sendo empreendidas para solucionar ou atenuar esse problema. Nesse âmbito, a criação de uma agência de atendimento automatizado acessível a todos os perfis de consumidor foi iniciada pela $* * *$ com vistas a tornar-se um ambiente que favoreça interações otimizadas com dispositivos computacionais e possibilitar a solicitação de serviços e informações, com pouco ou nenhum auxílio de humanos. Isso exigiu estudos envolvendo boas práticas de design de interação, de forma a efetivamente atender esse público-alvo. O presente trabalho descreve a solução iconográfica concebida para tornar as interfaces multimodais da nova agência mais eficazes e inclusivas. Essa eficácia foi mensurada tendo como referência os ícones atualmente utilizados na agência virtual da concessionária e aferida em dinâmicas com usuários.
\end{abstract}

Palavras-chave: Iconografia. Ícones. Inteligibilidade. Acessibilidade. Energia elétrica.

\begin{abstract}
Currently, it is estimated that 15\% of the world population have some kind of physical or sensory disability and over 20\% have low levels of literacy. Nowadays, the evolution of electronic devices grows rapidly with the increase of computing power and the creation of new devices. People with disabilities, however, often still face many barriers when interacting with these devices, which let them out of this digital society. In this sense, many initiatives have been taken to solve or mitigate this problem. In this sense, it was proposed by *** a project that is expected to create an agency with accessible customer service in order to be used by anyone. The aim of this project is to provide a physical environment in which everyone can order electrical services with little or no help from human facilitators through multimodal devices and interfaces. This led us to studies involving best practices of interaction design in order to effectively meet the target audience. This paper describes the iconographic solution designed to make multimodal interfaces more effective and inclusive. This efficacy was measured compared to a set of icons currently being used in a Web system of this company.
\end{abstract}

Keywords: Iconography. Icons. Intelligibility. Accessibility. Electrical energy.

\section{Introdução}

De acordo com os estudos da Organização Mundial da Saúde (2011), 15\% da população mundial possui algum tipo de deficiência, um número estimado de 1 bilhão de pessoas. Deficientes auditivos, por exemplo, correspondem a $2 \%$ da população total, totalizando mais de 124 milhões de indivíduos.

R. Eletr. do Alto Vale do Itajaí - REAVI, v. 4, n. 5, p. I- F, mar., 2016.

ISSN 2316-4190, DOI: 10.5965/2316419004052015065 


\section{REAVI}

Universidade do Estado de Santa Catarina

Centro de Educação Superior do Alto Vale do Itajaí

Nesse contexto, foi proposto um projeto para viabilizar soluções inovadoras de atendimento acessível aos clientes e consumidores da ***, incluindo pessoas idosas, com baixo letramento, com deficiência (visual, auditiva ou motora), ou com algum tipo de restrição temporária de mobilidade (com crianças de colo, por exemplo).

Dentro desse contexto mais amplo discutido anteriormente, encontram-se presentes a fundamentação e motivação para este estudo iconográfico. Os dispositivos tecnológicos previstos para a agência farão uso de ícones para facilitar a assimilação de conceitos pelos usuários (BEDFORD, 2014). Desse modo, é interessante retomar o conceito de Semiótica antes de qualquer coisa. Semiótica tem sua origem na palavra grega semeion, que significa signo. Assim, pode-se definir Semiótica Computacional como o estudo dos signos presentes nas interfaces homem-computadores - IHC. Esses signos podem representar qualquer elemento presente ou que, de alguma forma, faça uma alusão ao mundo real (NADIN, 1988).

Segundo Baranauskas et al. (1998) os signos das interfaces podem ser divididos em 6 categorias: signos interativos, atores, controladores, objetos, layout e fantasmas. Signos interativos, como exemplo, correspondem aos elementos das interfaces que podem ser diretamente manipulados pelos usuários, em outras palavras, disparam eventos em resposta às ações executadas como, por exemplo, os botões iconográficos.

Neste âmbito, no final dos anos 80, a teoria da ação de Donald Norman apresentou os chamados golfos de interação, representações hipotéticas onde eram criados gargalos entre o modelo mental dos usuários e dos designers, em outras palavras, eram criadas situações que distanciavam as expectativas de uns com os outros, o que acarretava danos à inteligibilidade das interfaces e dos sistemas como um todo. Assim, Norman enfatizou a necessidade de se encurtar esses golfos, aproximando metaforicamente o sistema da carga cognitiva dos usuários, com a construção de interfaces que atendessem as expectativas do público alvo (NORMAN, 1986).

Pelo modelo mental comentado anteriormente entende-se tratar daquilo que o usuário entende, ou pensa que entende, de um sistema. Esta representação é dita ser individual e, se não for dada a devida importância à criação destas estruturas, o desempenho das interfaces pode ser prejudicado. Em outras palavras, segundo Nielsen (2010):

"What users believe they know about a UI strongly impacts how they use it. Mismatched mental models are common, especially with designs that try something new. (Em uma tradução literal, o que os usuários pensam que sabem sobre uma interface influencia fortemente como eles a usam. Falhas nos modelos mentais são comuns, especialmente quando se propõe algo novo."

Por esses fatores pode-se ver a importância da criação de interfaces que atendam satisfatoriamente o público alvo, encurtando os golfos, de forma a aproximar os modelos mentais dos usuários aos dos designers. Os resultados desses esforços são interações amigáveis e maior satisfação dos usuários, além de menores taxas de rejeição da aplicação.

Nesse sentido, os signos das interfaces constituem aspectos distintos da interação e devem, portanto, ser cautelosamente estudados e projetados, em especial, aqueles que são responsáveis por metaforizar conceitos do mundo real. Esse é, por exemplo, o caso da iconografia do projeto proposto, cuja função é remeter aos serviços usualmente oferecidos ao público em agências de atendimento da concessionária de energia elétrica.

O presente trabalho tem como objetivo conceber e validar uma proposta de iconografia adequada para o uso nos terminais de autoatendimento acessíveis do projeto, com base na premissa de que a inteligibilidade icônica é consideravelmente aprimorada pelo embasamento em estruturas cotidianas do público alvo.

No que diz respeito aos estudos iconográficos que embasaram a elaboração desta pesquisa, pode-se dizer que foi levantada uma ampla literatura contendo boas práticas de projeto de 


\section{REAVI}

Universidade do Estado de Santa Catarina

Centro de Educação Superior do Alto Vale do Itajaí

aplicações (guidelines) voltadas ao público com necessidades especiais ou com alguma restrição de uso. Segundo Nielsen (1993) e Shneiderman (2009), guidelines de projeto de interfaces são diretrizes do bom projeto de protótipos que guiam designers e desenvolvedores na tomada de decisões acerca de uma IHC. Ademais, Shneiderman (2009) posiciona as guidelines em uma relação hipotética composta por quatro pilares, responsáveis por representar um projeto de IHC bem sucedido: requisitos, ferramentas de projeto, guidelines e testes de campo, fato que reforça a importância do uso de guidelines no design de sistemas.

Este artigo está organizado como se segue: Na Seção 2 discorre-se sobre trabalhos relacionados que foram encontrados na literatura. Na Seção 3 analisa-se a iconografia da agência virtual da concessionária e apresenta-se a proposta iconográfica deste trabalho. Na Seção 4 discorre-se sobre um estudo comparativo entre as duas coleções icônicas. Na Seção 5 discute-se uma avaliação realizada com objetivo de melhorar a confiabilidade dos dados. Por fím, na Seção 6 são feitas conclusões acerca deste estudo.

\section{Antecedentes na literatura}

Este estudo teve início com o levantamento de trabalhos correlacionados de aplicações multimodais acessíveis desenvolvidas e satisfatoriamente validadas no Brasil e no exterior. Nesses trabalhos buscou-se identificar diretrizes criadas pelos autores que precisaram equacionar o problema do bom projeto iconográfico.

Podem-se citar inicialmente os trabalhos de Ávila e Costa (2009) e de Medhi et al. (2007), os quais se propuseram a realizar um estudo comparativo verificando a inteligibilidade dos recursos multimídia para a apresentação de conceitos ao público iletrado ou semi-letrado. Por inteligibilidade entende-se tratar da capacidade de percepção e compreensão das coisas, dada toda a complexidade envolvida. Uma linha de pesquisa comum a ambos os trabalhos foi a verificação da efetividade de fotos para funcionar como ícones, ao invés de representações gráficas gerais. Ávila e Costa (2009) se destacaram ao proporem oficinas participativas com o público alvo das aplicações, com o respectivo envolvimento dos usuários no projeto dos ícones.

No trabalho de Paredes et al. (2014) são projetados ícones inclusivos para uma aplicação de pedido de socorro pelo smartphone baseando-se nas especificações das melhores práticas para o projeto de aplicações móveis, Mobile Web Application Best Practices (MWAB), da W3C (2008), além do Essentials for Cross-Disability Accessible Cell Phones, do The Board of Regents of the University of Wisconsin System (2010). Ambas as especificações assemelham-se em um aspecto: o de propor guias para o projeto de aplicações; a primeira delas, entretanto, carece de diretrizes voltadas à inclusão de pessoas com necessidades especiais, dado seu conteúdo consideravelmente mais genérico, fato que acaba não se confirmando com a segunda coleção.

Trabalho parcialmente relacionado foi o de autoria de Sayago e Blat (2009). Neste estudo foram observados os comportamentos de pessoas idosas ao interagirem com a Web na tentativa de se identificar quais são os principais problemas enfrentados por esse público. Entre os resultados apontados podem-se citar a descoberta de que a terminologia empregada nos botões iconográficos influencia a inteligibilidade dos usuários muito mais do que a comunicação visual empregada pelas formas gráficas propriamente ditas.

\section{Proposta de iconografia para o projeto}

Grande parte dos serviços de energia elétrica que serão oferecidos nessa agência física inclusiva são atualmente oferecidos em um sistema Web que oferece apoio iconográfico para a interação 


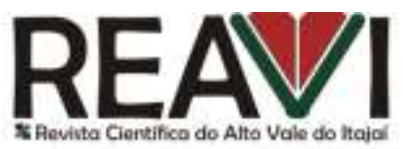

Universidade do Estado de Santa Catarina

Centro de Educação Superior do Alto Vale do Itajaí

com os serviços. São feitas a seguir algumas considerações acerca da solução iconográfica dessa agência virtual.

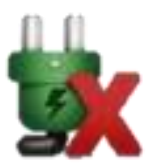

(a)

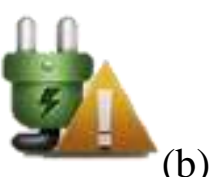

(b)

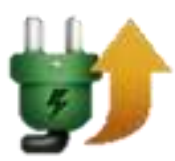

(c)

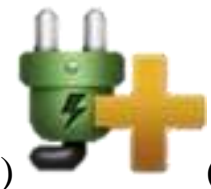

(d)

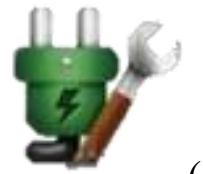

(e)

Figura 1 - Ícones da proposta iconográfica atual: (a) Estou sem luz; (b) Consultar interrupção programada; (c) Religação; (d) Ligação nova; (e) Corte para conserto.

Como mostrado na Figura 1, apesar de esteticamente atender algumas boas práticas de design como o bom contraste de cores para facilitar a discriminação dos ícones por pessoas com baixa visão (PICCOLO et al., 2010), a iconografia atual caracteriza-se por ser demasiadamente genérica e, por vezes, reaproveitar imagens em vários contextos, tornando os ícones menos distinguíveis uns dos outros. Nesse contexto, Ávila e Costa (2009) e Piccolo et al. (2010) defendem a prática de não se reaproveitar elementos visuais entre os ícones de uma mesma tela, de forma a minimizar o risco de confusão pelos usuários

Outro problema ilustrado na Figura 1 decorre da não inclusão de elementos cotidianos nas imagens (MEDHI et al., 2007; NORMAN, 1986), o que pode causar incompatibilidade dos ícones com o modelo mental que os usuários mantêm dos serviços oferecidos, prejudicando assim sua inteligibilidade. Vários autores sugerem que a cultura do público alvo seja incorporada às representações iconográficas de forma a facilitar a assimilação de conceitos (MEDHI et al., 2007; ÁVILA e COSTA, 2009; PICCOLO et al., 2010). Essa metaforização do conhecimento do usuário contribui positivamente para o entendimento da interface, uma vez que encurta o golfo existente entre os modelos mentais dos designers e do público-alvo, segundo Norman (1986). Nesse sentido, Nielsen (2014) argumenta que é melhor fazer os utilizadores de um sistema reconhecerem ao invés de relembrarem ou, em suas próprias palavras:

"Showing users things they can recognize improves usability over needing to recall items from scratch because the extra context helps users retrieve information from memory. (Em uma tradução literal, mostrar aos usuários coisas que eles possam reconhecer contribui para o aumento da usabilidade dos elementos ao invés de criá-los do zero, uma vez que o apoio em estruturas enraizadas do conhecimento os ajuda nesse processo)."

Ainda com relação à Figura 1, nota-se a presença de elementos visuais comuns ao contexto computacional, em especial nas ilustrações 1(a), para o serviço de "Estou sem luz", 1(b), para o serviço de "Consultar interrupção programada", 1(c), para o serviço de "Religação" e 1(d), para o serviço de "Ligação nova", a saber, a forma gráfica da letra "x", o uso de um sinal de exclamação, uma seta para cima e o sinal de mais "+". O entendimento dessas representações pressupõe um razoável nível de letramento digital, algo que se choca com a proposta de uma agência inclusiva, voltada a diversos perfis de usuário.

Alguns autores sugerem a realização de práticas de design participativo envolvendo sujeitos representativos do público a que o sistema se destina, de forma a captar elementos presentes no modelo mental dos participantes. Por exemplo, nos estudos de Ávila e Costa (2009) sobre sistemas de e-gov foi necessário criar ícones para representar profissionais da saúde, como médicos e dentistas. Os ícones criados incorporaram elementos distintivos para diferenciar as duas profissões. O ícone de médico, por exemplo, incluía um estetoscópio, ao passo que o de dentista trazia a cadeira de atendimento característica e a cuspideira, elemento marcante identificado em dinâmicas com usuários representativos. Em ambos os casos foi utilizado o elemento "cruz vermelha", solicitação feita pelos usuários representativos a fim de reforçar a associação à área da saúde. 
No contexto do projeto da agência automatizada da concessionária de energia elétrica foi proposta a concepção de ícones baseada em pequenas descrições da vida cotidiana do públicoalvo. Em outras palavras, foram idealizadas narrativas que melhor representassem a ação do botão (serviço) ao qual o ícone estava vinculado.

Para este trabalho, com a relação à metodologia de concepção dos ícones, o padrão visual adotado procurou manter consistência com o estilo de design de interfaces das novas linhas de produtos da Microsoft (2014), usada no Windows 8, Xbox 360, Zune, etc.), grosso modo, contendo no máximo três cores de bom contraste e tendo como essência o minimalismo. $\mathrm{O}$ motivo dessa escolha deve-se ao framework dotNET que foi escolhido para o desenvolvimento dos softwares dos terminais multimodais. Assim, lista-se na Tabela 1 a representação visual de alguns serviços idealizada nesse trabalho, além dos ícones atuais do sistema Web dessa concessionária, como um comparativo.

\begin{tabular}{|c|c|c|c|}
\hline Serviço & $\begin{array}{l}\text { Sistema Web da } \\
\text { Concessionária }\end{array}$ & Proposta - Minimalista & $\begin{array}{l}\text { Cenário } \\
\text { idealizado }\end{array}$ \\
\hline Troca de titularidade & & & $\begin{array}{l}\text { Simbolismo de } \\
\text { uma troca } \\
\text { realizada entre } 2 \\
\text { indivíduos } \\
\text { nitidamente } \\
\text { distintos }\end{array}$ \\
\hline Informar leitura & & & $\begin{array}{l}\text { Personagem com } \\
\text { aparência rural } \\
\text { ligando para } \\
\text { informar a leitura } \\
\text { à companhia } \\
\text { elétrica. }\end{array}$ \\
\hline $\begin{array}{lll}\text { Imprimir } & \text { cartão } & \text { de } \\
\text { autoleitura } & & \end{array}$ & & & $\begin{array}{l}\text { Impressora } \\
\text { contendo um } \\
\text { cartão de } \\
\text { autoleitura sendo } \\
\text { impresso. }\end{array}$ \\
\hline Estou sem luz & & & $\begin{array}{l}\text { Personagem com } \\
\text { vela acesa } \\
\text { próxima, se } \\
\text { sentindo mal por } \\
\text { estar sem luz. }\end{array}$ \\
\hline
\end{tabular}

Tabela 1 - Proposta iconográfica.

\section{Avaliação da proposta iconográfica}

Dada a necessidade de se realizar um estudo de inteligibilidade para aferir a efetividade dos ícones, optou-se por uma abordagem mais cômoda para os participantes, em que os questionários poderiam ser respondidos remotamente.

Para isso, foram criados dois questionários distintos (Padrão A - Sistema Web; Padrão B Proposta deste trabalho). Neste estudo optou-se por um arranjo em que cada participante somente responderia ao questionário referente a uma única coleção. Essa estratégia visou eliminar a influência que uma coleção poderia ter sobre a outra.

No que trata da definição das amostras populacionais, partiu-se da lista de e-mails de duzentos colaboradores pré-selecionados para a atividade, tendo sido descartados aqueles que tivessem algum vínculo com o estudo em questão. Os colaboradores habilitados foram então 


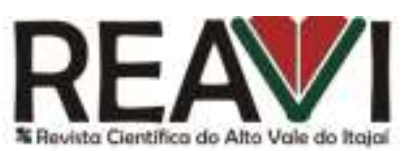

Universidade do Estado de Santa Catarina

Centro de Educação Superior do Alto Vale do Itajaí

aleatoriamente divididos em dois grupos de cem pessoas cada. A cada grupo foi submetido o questionário de uma das coleções de ícones.

O envio do e-mail com o convite para participação no estudo ocorreu em setembro de 2014. Os formulários ficaram disponíveis para resposta por 5 dias. Ao final desse período foi obtido um total de 88 respostas, 44 para cada coleção.

O tempo médio de resposta projetado para ambos os questionários foi de dez minutos, com dezessete ícones cada, de forma a não desmotivar os participantes convidados.

Os ícones avaliados neste estudo foram referentes aos serviços de: segunda via de conta, imprimir cartão de leitura, alterar vencimento da conta, troca de titularidade, consultar interrupção programada, troca de disjuntor, reembolso por danos elétricos, informar pagamento de conta, alterar endereço de entrega da conta, atualizar meios de contato, poda de árvores, informar leitura, estou sem luz, conta por email, ligação nova, religação e corte para conserto.

Ambos os instrumentos de estudo foram similares na maneira como fizeram a coleta de dados, isto é, eram compostos de quatro etapas:

1. Apresentação do estudo e coleta de dados sociodemográficos dos participantes;

2. Estudo da interpretação visual de alguns ícones sem apoio textual;

3. Questionário em que os participantes precisavam relacionar os ícones aos serviços que melhor os representavam;

4. Dados de satisfação subjetiva com relação ao padrão visual dos ícones.

Os dados sociodemográficos tiveram por objetivo descrever melhor os dois grupos populacionais, com perguntas que visavam identificar:

- O sexo do respondente;

- A faixa etária do respondente;

- Sua frequência de utilização de serviços online de energia elétrica;

- Sua experiência com projetos de concessionárias de energia elétrica.

Com relação ao sexo dos participantes, pode-se dizer que ambas as amostras foram similares, não havendo grande polarização para nenhum grupo em especial (Padrão A - Masculino: 59\% / Feminino: 41\%; Padrão B - Masculino: 66\% / Feminino: 34\%). Uma curiosidade diz respeito à maior presença de respondentes do sexo masculino do que feminino em ambos os grupos, o que tão somente reflete a repartição dos gêneros na instituição em que o estudo ocorreu.

A idade dos participantes em ambos os questionários mostra uma concentração maior de pessoas na faixa etária de 20 a 30 anos e de 31 a 40 anos (Padrão A - De 20 a 30: 45\% / De 31 a 40: 41\% / De 41 a 50: 7\% / Acima de 50: 7\%; Padrão B - De 20 a 30: 43\% / De 31 a 40: 23\% / De 41 a 50: 20\% / Acima de 50: 14\%). Em nenhum questionário houve respostas de pessoas abaixo dos 20 anos. No questionário do Padrão A houve uma proporção de participantes acima de 41 anos ligeiramente maior que no do Padrão B.

Embora tenha-se obtido uma população predominantemente jovem para ambos os questionários, parte significativa dos respondentes reportou já ter feito uso de serviços de energia elétrica em sistemas Web (Padrão A - Sim: 52\% / Não: 48\%; Padrão B - Sim: 41\% / Não: 59\%). Nesse sentido, usuários com experiência sobre um domínio tendem a apresentar melhores resultados ao responderem questionamentos sobre ele. Em outras palavras, as chances de uma pessoa não conhecer do que se trata um serviço são reduzidas devido à experiência prévia adquirida.

Por fim, a pergunta referente à experiência com projetos de concessionárias de energia elétrica dentro da instituição de pesquisa apontou que a maioria dos participantes não havia tido a oportunidade de trabalhar em contextos semelhantes, o que, no caso do presente estudo, caracteriza-se por ser um cenário mais interessante, de modo que as chances de essas pessoas já conhecerem ícones ou mesmo representações visuais em contextos de outras agências são reduzidas (Padrão A - Sim: 41\% / Não: 59\%; Padrão B - Sim: 43\% / Não: 57\%). 


\subsection{Resultados}

Como análise inicial dos dados foram utilizadas contagens de frequência para os palpites dos participantes em cada um dos ícones, isto é, no ícone de "segunda via de conta", quantos haviam escolhido corretamente "segunda via de conta", quantos escolheram "conta por e-mail", quantos optaram por "alterar data de vencimento da conta", e assim sucessivamente. Esse tipo de tratamento dos dados permitiu ainda que o desempenho dos ícones em ambas as coleções fosse comparado. Em outras palavras, foi possível identificar qual ícone havia obtido o maior número de acertos. A quantidade balanceada de participantes nas amostras do questionário do Padrão A e da proposta B permitiu que comparações do tipo fossem realizadas.

Em linhas gerais, pode-se dizer que $65 \%(\mathrm{n}=10)$ dos ícones da proposta do Padrão B foram mais inteligíveis que os correspondentes do Padrão A. Por volta de 17\% $(n=3)$ dos ícones da proposta alternativa B foram tão inteligíveis quanto os correspondentes do Padrão A. Por fim, 23\% $(\mathrm{n}=4)$ dos ícones da proposta B foram um pouco menos inteligíveis que os respectivos do Padrão A.

De maneira geral, a lista de serviços para os quais a proposta deste trabalho (Padrão B) se sobressaiu ao padrão do sistema Web (A) diz respeito a:

- $\quad$ Segunda via de conta (B:95\% x A:39\%);

- Imprimir cartão de leitura (B:93\% x A:2\%);

- Alterar vencimento da conta (B:98\% x A:66\%);

- $\quad$ Troca de titularidade (B:89\% x A:59\%);

- Consultar interrupção programada (B:70\% x A:45\%);

- $\quad$ Troca de disjuntor (B:93\% x A:68\%);

- Reembolso por danos elétricos (B:93\% x A:57\%);

- Informar pagamento de conta (B:86\% x A:70\%);

- Alterar endereço de entrega da conta (B:100\% x A:82\%);

- Atualizar meios de contato (B:84\% x A:55\%).

Em outras palavras, esses foram os serviços mais bem entendidos a partir da abordagem iconográfica proposta neste trabalho. Por outro lado, os seguintes serviços tiveram índices similares de acerto entre as duas coleções icônicas, A e B:

- $\quad$ Poda de árvore (A:100\% x B:98\%);

- Informar leitura (A:77\% x B:75\%);

- $\quad$ Estou sem luz (B:95\% x A:91\%).

Por fim, alguns serviços no Padrão B foram menos inteligíveis que os do Padrão A:

- Conta por e-mail (A:93\% x B:70\%);

- $\quad$ Ligação nova (A:73\% x B:45\%);

- $\quad$ Religação (A:68\% x B:52\%);

- Corte para conserto (A:73\% x B:45\%).

\section{Análise da significância dos resultados dos estudos icônicos de inteligibilidade}

As contagens de frequência usadas no capítulo anterior para os dados do questionário online são boas para análises rápidas e overviews dos cenários estudados. No entanto, pode-se dizer que elas podem não mostrar fielmente aquilo que se espera, em outras palavras, a significância dos dados representados. Por exemplo, estas representações sozinhas não são capazes de responder se os padrões observados refletem de fato o desempenho da população ou se são devido a algum acaso oriundo da amostragem aleatória dos participantes. Deste modo, pode-se dizer que é 


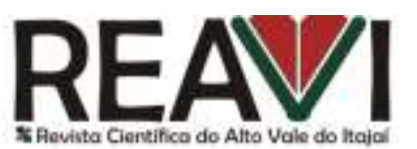

Universidade do Estado de Santa Catarina

Centro de Educação Superior do Alto Vale do Itajaí

possível verificar estas relações estatisticamente, mais especificamente com auxílio do método de qui quadrado (PEARSON, 1900).

O teste de qui quadrado $\left(\mathrm{x}^{2}\right)$ é um método estatístico usado para analisar dados nominais (em outras palavras, de frequência) ao invés de dados numéricos (PEARSON, 1900). Este teste requer designs de experimentos between-subject (LAZAR et al., 2009), ou seja, quando os participantes de um estudo interagem com somente uma das condições da variável independente - o que é válido no caso deste estudo, pois cada participante respondeu somente um questionário online.

Para o teste de qui quadrado, assim como para qualquer outro teste estatístico, faz-se necessário a definição de hipóteses que serão aceitas ou refutadas. Assim, para o caso deste experimento, propõe-se abaixo a hipótese nula (H0, em outras palavras, quando os resultados do experimento não são conclusivos), seguida pela hipótese alternativa (H1, em outras palavras, quando pode-se afirmar com grande grau de certeza que os efeitos observados são de fato válidos):

- H0: Não existe diferença na inteligibilidade dos ícones presentes no Padrão A e no Padrão B.

- H1: Existe diferença na inteligibilidade dos ícones presentes no Padrão A e no Padrão B.

Outro fator importante de um teste estatístico diz respeito ao valor de $\mathrm{p}$ calculado por ele, ou seja, um número real que informa o grau de significância com que se pode rejeitar a hipótese nula e aceitar a alternativa. Assim, convenciona-se falar que valores de $\mathrm{p}<0.01$ apresentam 99\% de confiança e valores de $\mathrm{p}<0.05$ apresentam 95\%. Valores acima de 0.05 não são considerados estatisticamente relevantes (LAZAR et al., 2009). Por exemplo, em um estudo com qui quadrado em que o p obtido seja igual a 0.00324 , rotula-se $\mathrm{p}<0.01$ e rejeita-se a hipótese nula com $99 \%$ de confiança, aceitando assim a alternativa. Agora, em um estudo que retorna $\mathrm{p}$ como sendo igual a 0.498 (em outras palavras, $\mathrm{p}>0.05$ ), aceita-se a hipótese nula, a de que as relações observadas não são válidas.

Para as hipóteses definidas anteriormente pode-se observar dois tipos de variáveis de análise, uma independente e outra dependente. Em estatística, chama-se de variável independente aquela em que se controla durante o experimento e não depende de nenhuma outra variável - no caso, a coleção icônica, Padrão A ou Padrão B. Variável dependente, por sua vez, pode ser definida como sendo aquela que se observa com base em uma ou mais independentes - no caso, a inteligibilidade (LAZAR et al., 2009).

Um fator essencial para a análise com o método de qui quadrado diz respeito à organização dos dados em uma tabela de contingência, composta essencialmente por uma matriz $2 \times 2$ em que se colocam as condições da variável independente nas linhas e as observações da variável dependente nas colunas, sumarizadas por meio de contagens numéricas. Portanto, pode-se dizer que para análise dos dados deste trabalhado, foram criadas tabelas de contingência que continham as informações de acertos e erros para cada uma das propostas trabalhadas.

\subsection{Resultados}

Para o caso do ícone de segunda via de conta, de acordo com a sumarização dos resultados do capítulo anterior, o Padrão B foi aferido corretamente por $95 \%$ dos participantes enquanto o Padrão A apresentou apenas 38\% dos acertos. Assim, os valores calculados pelo teste de qui quadrado são dados por: $\mathrm{x}^{2}=29.6248, \mathrm{df}=1, \mathrm{p}=5.243 \mathrm{e}-08$. Portanto, pode-se afirmar que o ícone do Padrão B é mais inteligível que seu correspondente do Padrão A com $99 \%$ de confiança $(\mathrm{p}<0.01)$.

Com base nos resultados do capítulo anterior, pode-se observar novamente uma grande quantidade de acertos para o ícone de imprimir cartão de leitura no Padrão B (93\%) frente ao 


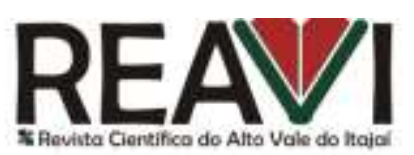

Universidade do Estado de Santa Catarina

Centro de Educação Superior do Alto Vale do Itajaí

Padrão A (4\%). No caso, os valores calculados pelo teste de qui quadrado foram: $\mathrm{x}^{2}=62.2273$, $\mathrm{df}=1, \mathrm{p}=3.06 \mathrm{e}-15$. Portanto, pode-se afirmar novamente que o ícone de imprimir cartão de leitura do Padrão B é mais inteligível que o do Padrão A com 99\% de confiança $(\mathrm{p}<0.01)$.

Para o ícone de alterar o vencimento da conta houve uma distribuição mais igualitária de acertos e erros no Padrão A; entretanto, o Padrão B concentrou 97\% de acertos. Para este caso, pode-se afirmar também que o ícone do Padrão B foi mais inteligível que seu correspondente do Padrão A com $99 \%$ de confiança $\left(x^{2}=12.9097, \mathrm{df}=1, \mathrm{p}=0.0003269\right)$.

No caso do ícone de troca de titularidade, o Padrão B foi capaz de aferir $88 \%$ dos acertos, enquanto o Padrão A apenas 59\%. Deste modo, ao avaliar estatisticamente esta relação obtém-se novamente $99 \%$ de confiança $(\mathrm{p}<0.01)$ de que o Padrão B é mais inteligível que o Padrão A ( $\mathrm{x}^{2}$ $=8.4763, \mathrm{df}=1, \mathrm{p}$-value $=0.003598)$.

Para o caso do ícone de consultar interrupção programada, ambos os padrões foram mais balanceados com relação à quantidade de acertos e erros. O Padrão $\mathrm{B}$ obteve $70 \%$ dos acertos, enquanto o Padrão A apenas 44\%. Agora, no entanto, afirma-se que o Padrão B é mais inteligível que o A com $95 \%$ de confiança $(\mathrm{p}<0.05)\left(\mathrm{x}^{2}=4.6635, \mathrm{df}=1\right.$, $\mathrm{p}$-value $\left.=0.03081\right)$.

Troca de disjuntor foi outro ícone que apresentou melhor inteligibilidade na proposta do Padrão B com 99\% de confiança ( $<$ < 0.01). Sendo assim, pode-se afirmar que os $70 \%$ de acerto obtido por ele frente aos $45 \%$ do Padrão A são significantes, rejeitando-se a hipótese nula de que não há diferença entre a inteligibilidade de ambas as propostas. Os valores de qui quadrado para este caso são dados por $\mathrm{x}^{2}=7.2908, \mathrm{df}=1, \mathrm{p}$-value $=0.006931$.

Ao observar o comportamento do ícone de reembolso por danos em ambas as propostas, pode-se notar que o Padrão B aferiu $93 \%$ dos acertos frente aos $56 \%$ do outro padrão. Assim, pode-se afirmar também que a inteligibilidade do Padrão B é melhor que a do Padrão A com $99 \%$ de significância $\left(\mathrm{p}<0.01\right.$ ), com os valores de qui quadrado sendo dados por $\mathrm{x}^{2}=13.6364$, $\mathrm{df}=1, \mathrm{p}$-value $=0.0002218$.

No caso do ícone do serviço de informar pagamento de conta, apesar de ambas as propostas terem tido bons percentuais de acerto (Padrão A: $70 \%$ x Padrão B: 86\%), o estimador de qui quadrado não foi capaz de aferir a significância destes dados, tendo produzido valores na ordem $\mathrm{de}^{2}=2.4165, \mathrm{df}=1, \mathrm{p}$-value $=0.1201$. Isso não necessariamente significa que uma proposta é pior em relação à outra, mas que esses resultados podem ter sido causados por algum acaso da amostragem populacional (por exemplo, a existência de algum viés que possa ter alterado os dados). Assim, sugere-se que estes ícones sejam re-testados em um novo experimento, contendo uma nova amostragem de indivíduos com características similares. Ademais, ao se aceitar a hipótese nula neste caso com p > 0.05 (a de que não há diferença de inteligibilidade entre as propostas), pode-se ainda sugerir que ambas as propostas são igualmente inteligíveis.

Para o ícone do serviço de alterar endereço de entrega da conta pode-se dizer que o estimador voltou a apresentar um grande nível de significância, com $\mathrm{p}<0.01$. Sendo assim, o Padrão B foi mais inteligível que o Padrão A em $100 \%$ das vezes $\left(x^{2}=6.7375\right.$, df $=1$, p-value $\left.=0.009441\right)$, com $99 \%$ de confiança.

O Padrão B do ícone de alterar meios de contato foi mais inteligível que o Padrão A em 84\% das vezes. No caso, o Padrão A aferiu apenas 54\% dos acertos. Os valores de qui quadrado para essa análise são dados por $\mathrm{x}^{2}=7.694, \mathrm{df}=1, \mathrm{p}$-value $=0.005541$, o que permite afirmar com $99 \%$ de certeza $(\mathrm{p}<0.01)$ que essa relação observada é de fato válida.

Para os próximos três casos de ícones serão mostradas observações de desempenho em que estimador de qui quadrado não foi capaz de produzir resultados fidedignos devido à similaridade existente entre a razão de acertos e erros dos participantes. O ícone para o serviço de estou sem luz, por exemplo, foi aferido corretamente em $90 \%$ dos casos do Padrão A e $95 \%$ do Padrão B. A priori, subjetivamente falando pode-se considerar esses desempenhos como sendo muito bons para ambas as propostas, entretanto, para fins estatísticos é necessário que ocorra variância entre 


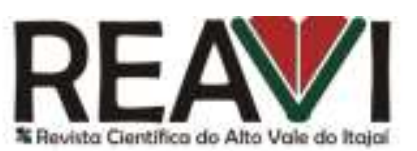

Universidade do Estado de Santa Catarina

Centro de Educação Superior do Alto Vale do Itajaí

as observações (LAZAR et al., 2009). No caso, os valores de qui quadrado foram: $x^{2}=0.1789$, df $=1, \mathrm{p}$-value $=0.6724$, o que leva a uma aceitação da hipótese nula, a de que não há diferença entre a inteligibilidade das duas propostas, sendo ambas igualmente inteligíveis.

O ícone do serviço para poda de árvores foi outro caso que foi prejudicado pela ausência de variância entre as observações, o qual nem foi capaz de ser avaliado pelo teste de qui quadrado, tendo obtido valores na ordem $\mathrm{de}^{2}=0, \mathrm{df}=1, \mathrm{p}$-value $=1$. Novamente, aceita-se a hipótese nula de que não há diferença entre a inteligibilidade de ambas as propostas (são iguais).

De maneira semelhante ao ocorrido com o ícone anteriormente discutido, a representação icônica para o serviço de informar leitura obteve pouco, ou nenhum, grau de variância entre as observações, o que impossibilitou o teste de significância pelo método estatístico adotado de ser realizado.

Agora, com relação ao ícone de conta por email, em que o Padrão A se sobressai ao B no quesito inteligibilidade (Padrão A: 93\% x Padrão B: 70\%), os valores de qui quadrado para este teste são dados por $\mathrm{x}^{2}=6.1875, \mathrm{df}=1, \mathrm{p}$-value $=0.01287$. Portanto, rejeita-se a hipótese nula de que não há diferença na inteligibilidade dos padrões com $95 \%$ de significância $(p<0.05)$ - no caso, com o Padrão A sendo melhor que o B.

Para o caso do ícone de ligação nova, a sumarização do capítulo anterior mostra uma relação de $72 \%$ de acerto do Padrão A frente aos $44 \%$ do Padrão B. Sendo assim, rejeita-se também a hipótese nula e assume-se o Padrão A como mais inteligível com $95 \%$ de significância $\left(\mathrm{x}^{2}=\right.$ $5.688, \mathrm{df}=1, \mathrm{p}<0.05)$.

Apesar dos 68\% dos acertos do Padrão A para o ícone de religação frente ao Padrão B, não se pode rejeitar a hipótese nula de que não há diferença entre as inteligibilidades e assumi-lo como mais inteligível dados os resultados de qui quadrado obtidos, $\mathrm{x}^{2}=1.7078$, $\mathrm{df}=1, \mathrm{p}$-value $=$ 0.1913 .

Por fim, o último dos casos analisados, o ícone de corte para conserto, obteve valores de qui quadrado na ordem de $\mathrm{x}^{2}=5.688, \mathrm{df}=1, \mathrm{p}$-value $=0.01708$, o que leva a uma rejeição da hipótese nula, de que não há diferença de inteligibilidade entre os ícones testados para este serviço $(\mathrm{p}<0.05)$.

\section{Conclusão}

Embora sejam de extrema importância para a compreensão das interfaces, os ícones usualmente são criados com base na assertividade tecnológica tradicional presente no cotidiano de usuários letrados digitalmente - em outras palavras, fazendo uso extensivo de representações que aludem aos computadores, disquetes, setas, etc. Este cenário, no entanto, não é válido quando se trata de um público mais amplo, que nem sempre possui famililaridade com computadores - no caso, o da agência inclusiva. Idosos, pessoas com baixo letramento e com baixa visão, por exemplo, podem apresentar extremas dificuldades ao se depararem com ícones com os quais usuários experientes no uso de computadores estão acostumados (pequenos, com excesso de detalhes, com contraste errado de cores, obscuros, etc.), o que pode acarretar em danos à inteligibilidade dos sistemas como um todo. Por estes e outros fatores evidencia-se a necessidade do bom projeto icônico para as aplicações, em outras palavras, aquele que atenda de maneira satisfatória a maior parcela possível de usuários do sistema. Vale lembrar que os ícones possuem a característica fundamental de servirem como uma forma de redundância positiva à interpretação textual da terminologia das interfaces, o que acaba aliviando a carga cognitiva sobre os utilizadores.

Nesse contexto, o presente trabalho teve por objetivo descrever o resultado de um esforço de concepção de uma iconografia adequada para os terminais multimodais acessíveis propostos no escopo da agência inclusiva de atendimento aos clientes da ***. Ao longo do trabalho foram realizados estudos das boas práticas para o projeto de representações iconográficas inteligíveis, 
bem como o levantamento de trabalhos correlatos. Com base nessas informações, foi elaborada uma proposta iconográfica de representação dos serviços da agência. Esta abordagem foi validada quanto à sua inteligibilidade, por meio de uma dinâmica participativa. Foram também conduzidos estudos com os ícones atualmente presentes no sistema Web da concessionária. A comparação da inteligibilidade de ambas as coleções possibilitou entender o desempenho de cada uma delas.

A proposta alternativa idealizada por esse trabalho mostrou-se, de maneira geral, mais inteligível que a coleção que é atualmente utilizada, o que tão somente reflete a premissa intríseca investigada, e validada, de que o projeto de ícones inteligíveis deve ter embasamento em vivências cotidianas do público alvo, de forma a facilitar a assimilação dos conceitos, assim como adotado neste trabalho na construção das estórias propostas. As representações gráficas propostas irão viabilizar interações mais inteligíveis aos usuários desta agência, o que irá contribuir positivamente quando os usuários precisarem escolher algum serviço para interagir.

Como sugestão de trabalho futuro sugere-se a expansão da amostragem de indivíduos para as demais parcelas representativas do público alvo da agência inclusiva, o que irá contribuir significativamente para aperfeiçoar a qualidade dos significados dos ícones propostos, possibilitando verificar eventuais falhas presentes, além de orientar a criação de ícones para novos serviços.

\section{Referências}

ANDERSEN, P.B. (1997) A theory of computer semiotics. New York: Cambridge University Press.

ÁVILA, I.M.A.; COSTA, R.G. (2009) Ícones como facilitadores da interação de usuários iletrados com interfaces computacionais. Cadernos CPqD Tecnologia, vol. 5, n. 2, pp. 15-36.

BARANAUSKAS, M.C.; ROSSLER, F.; de OLIVEIRA, O.L. (1998) Uma abordagem semiótica à análise de interfaces: um estudo de caso. In: I Workshop sobre Fatores Humanos em Computação.

Disponível:

http://www.unicamp.br/ ihc99/Ihc99/AtasIHC99/AtasIHC98/Baranauskas.pdf.

Acesso:

21/08/2014.

BEDFORD, A. (2014) Icon usability. NNGroup Usability Report. Disponível: http://www.nngroup.com/articles/icon-usability/. Acesso: 22/08/2014.

LAZAR, J.; FENG, J.H.; HOCHHEISER, H. (2009) Research Methods in Human-Computer Interaction. Wiley.

MEDHI, I.; SAGAR, A.; TOYAMA, K. (2007) Text-free user interfaces for illiterate and semiliterate users. The MIT Press, vol. 4, n. 1, pp. 37-50.

Microsoft (2014) Microsoft design language: Guidelines for typography. Disponível: http://msdn.microsoft.com/en-us/library/windows/apps/jj553415.aspx. Acesso: 16/10/2014

NADIN, M. (1988) Interface design: a semiotic paradigm. Semiótica, v. 109, n. 3/4, pp. 269302.

NIELSEN, J. (1993) Usability engineering. Boston: Academic Press. 


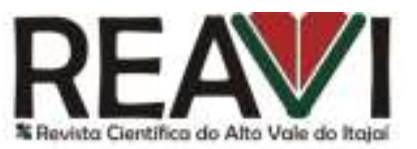

Universidade do Estado de Santa Catarina

Centro de Educação Superior do Alto Vale do Itajaí

NIELSEN, J. (2010) Mental models. NNGroup Usability Report. Disponível: http://www.nngroup.com/articles/mental-models/. Acesso: 21/08/2014.

NIELSEN, J. (2014) Memory recognition and recall in user interfaces. NNGroup Usability Report. Disponível: http://www.nngroup.com/articles/recognition-and-recall/. Acesso: 22/08/2014.

NORMAN, D. (1986) Cognitive engineering. In: Norman, D.A., Draper, S.W. (eds), User centered design in new perspectives on human-computer interaction. Hillsdale: Lawrence Erlbaum Associates.

PAREDES, H.; FONSECA, B.; CABO, M.; PEREIRA, T.; FERNANDES, F. (2014) SOSPhone: a mobile application for emergency calls. Univ. Access. Inf. Soc., vol. 13, pp. 277-290.

PEARSON, K. (1900) X. On the criterion that a system of deviations from the probable in the case of a correlated system of variables is such that it can be reasonably supposed to have arisen from random sampling. Philosophical Magazine Series 5, vol. 50, pp. 157-175.

PICCOLO, L.S.G.; SCHMIDT, C.P.; OSORIO, A.F.S.; DUARTE, R.E.; ÁVILA, I.M.A.; TAMBASCIA, C.A.; CARVALHO, R.F.; AURELIANO, M.G.; ROLIM, L.A.G. (2010) Modelo de interação inclusivo para interfaces de governo eletrônico. Cartilha Fundação CPqD.

ROCHA, H.V.; BARANAUSKAS, M.C. (2005) Design e avaliação de interfaces humanocomputador. 3. ed. Nied, Unicamp.

SAYAGO, S.; BLAT, J. (2009) About the relevance of accessibility barriers in the everyday interactions of older people with the web. In: Proceedings of the 18th International World Wide Web Conference, W4A2009, Madrid, Spain.

SHNEIDERMAN, B. (2009) Designing the user interface: strategies for effective humancomputer Interaction. 4th ed. Boston: Addison-Wesley Longman, Inc.

The Board of Regents of the University of Wisconsin System (2010) Essentials for crossdisability accessible cell phones. Disponível em: http://trace.wisc.edu/docs/2010-phoneessentials/index.php. Acesso: 15/08/2014.

W3C (2008) Mobile web application best practices (MWABP) 2.0. Disponível em: http://www.w3.org/TR/mwabp/. Acesso: 15/08/2014.

WHO (2011) World report on disability. Disponível: http://www.who.int/disabilities/world_report/2011/report.pdf. Acesso: 15/10/2014. 